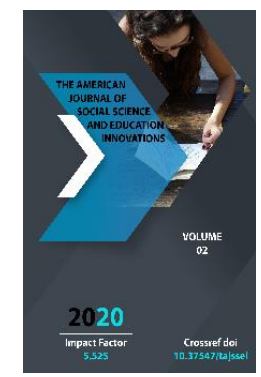

\title{
Formation Of Students 'Practical Skills In Technical Higher Education Institution And Production Enterprise
}

\author{
Uygun Abdullayevich Urinov \\ Doctor Of Philosophy In Pedagogical Sciences (PhD), Bukhara Engineering Technological \\ Institute, Uzbekistan
}

Copyright: Original content from this work may be used under the terms of the creative commons attributes 4.0 licence.

\section{ABSTRACT}

This article presents methods and techniques for shaping and developing students' practical skills through collaboration between the higher education systems and manufacturing enterprises. At the same time, the concept of "Learning" is widely covered by students: learning by imitation, by habit, by success, by trying, by making mistakes, by learning, by comprehension, by understanding. This reflects a four-step approach to develop practical skills of the student. Step 1 - Explanation - Interest Information. Step 2 - Demonstration. Step 3 - Return as shown. Step 4 - Practise. The following scientific conclusions are made on the "four-step" method of learning: 1. Assimilation (learning), 2. "Learning through conditional reflexes" through repetition, 3. Stimulation (praise) on the results achieved in mastering. It is shown that actions within the reference text method are performed as follows: 1. Data collection. 2. Planning. 3. Decision making. 4. Implementation. 5. Checking. 6. Conclusion. In order to apply the project method in the whole process of practical training, the projects will be as follows: 1. Exact limited task, 2. Task is complex from the point of view of students and requires them to apply existing knowledge in other situations. 3. Independently perform a new task according to the plan with the acquired knowledge and skills. Students are described to use methods to build their skills and competencies at a high level through reference text and project methods. In the final stage, methods of assessing the practical skills formed in students are presented.

\section{KEYWORDS}

Learning, comprehension, higher education, production, learning process, collaboration, problem, attempt, exercise, evaluation. 


\section{INTRODUCTION}

One of the main requirements in higher education is the preparation of students in accordance with the requirements of the labor market through cooperation between the higher education system and industrial enterprises. This is reflected in the Resolution of the President of the Republic of Uzbekistan dated April 20, 2017 No PD-2909 "On measures to further develop the system of higher education." The decision was made in order to radically reconsider the content of training in accordance with the priorities of socioeconomic development of the country, to create the necessary conditions for the training of specialists with higher education at the level of international standards [1].

The concept of "learning" in students is understood as the acquisition of new types of practical skill or the change of an existing skill. In this interaction, the concept of "skill" means the followings the application of knowledge and a person's reaction to the views of a particular activity. We define this concept more precisely: Learning is a process in which a student changes a skill through his or her relationship with the natural environment and the experience gained from it. So, the skill includes goals, opportunities and forms. Through learning, students gain insight, their own opinion, knowledge skills and abilities. New forms of knowledge and results are exact evidence of successful learning.

Types of learning. Learning can take place in a variety of situations: through imitation; because of habit; because of success; due to trial and error; by comprehension and by understanding.

Learning by imitation. Imitation is accepting the moral patterns of other teachers and imitating them in the same way. This process can take place consciously or unconsciously. This type of learning is most effective in teaching movements. This type of learning can also be observed in daily life. For example, children can imitate their parents or young people can imitate their heroes.

Because of habit. This type of learning is described as learning through conditional reflex or classical formulation. Conditional reactions play an important role in the formation of habits, the emergence of types of behavior aimed at preventing accidents.

Because of success. This method of learning is described as operational conditioning and involves a process in which the systematic study of conditional reactions is carried out with the help of learning achievements. Every step of a student done towards independent learning and performance is observed, and if he achieves above-average level of mastery, it is recognized with praise. Praise is considered a conditional observer. If the behavior is repeated frequently, which aimed at correctly solving problems, and then this behavior will be remembered for a long time.

\section{THE MAIN PART}

Learning through attempt, making mistakes and success. This method is related to operational conditioning, but here the feeling of success is not necessary, this method is initially associated with an incomprehensible complex situation. In this case, a complex situation must be resolved through "attempts". In this case failed wrong solutions will not be returned later. The right solutions, on the other hand, are determined by success or partial success and will be remembered for a long time. This method is time consuming, very anxious, and because it is based on 
chance, it should only be used when you need to practice problem-solving behaviors.

Learning through comprehension. Comprehension refers to "seeing and understanding a connection" that has never been seen before. Here the processes, events, cause-and-effect relations, which were previously incomprehensible, are mastered mentally. "Understanding" is the result of a mental process. At the same time, new interactions are formed during data processing by rearranging and structuring them. It is not possible to solve these problems on the spot, which means that all the various solutions offered must be considered at the level of thought, i.e. imagination, the solution of the problem arises and is understood suddenly, and can then be used without exercise for mental action [2].

The teacher can use a variety of methods of conscious learning in the transition to activity exercises. It emphasizes the need to pay more attention to the method of learning through 'comprehension, understanding', as it is distinguished by its long-lasting effect.

In the educational process, students will need to study specific subjects in depth so that they have the opportunity to shape their chosen professional skills. To this end, it is important that teachers organize the learning process through the use of advanced methods of teaching special subjects. The "four-step method" is the most effective method of conducting practical training in special subjects. This method is widely used in the education of the Republic of Uzbekistan, the United States and several European countries. The process of mastering practical skills in this method is carried out in the following four stages.

The internship teacher gives the students a smaller task to be done first, and then demonstrates in practice the order in which it will be completed. The student must then return the work as shown. As the student returns, the internship teacher corrects his or her mistakes. The student should repeat this exercise several times [3].

Step 1 - Explanation - Interest - Information. The course begins with arousing students' interest in the field and related topics. Then the teacher explains to the students the information to complete the practical lesson and the process to be performed in it. In this case, the teacher can use all the teaching materials, diagrams, instructions, tools, visual aids. The internship teacher explains the sequence of preparatory work to be done.

Step 2 - Demonstration. At this stage, the practice teacher explains the steps of the work itself. It is recommended to demonstrate practical skills 3 times.

- The demonstration is held at a simple pace so that students have a complete and realistic image.

- Each work phase is displayed separately and at low speed to better demonstrate its features.

- Is shown once again in full at a normal speed to create a clear picture in students.

Step 3 - Repeat as shown: Each student repeats the characters of the internship teacher as shown. While students are working, the teacher corrects their mistakes. He praises good work and criticizes bad work.

Step 4 - Training. The work can be terminated if the results of the work performed by students fully meet the quality criteria. Students in the first and second stages should have an initial theoretical knowledge. Therefore, the following scientific conclusions can be made on the "four-step" method of study: 
1. Assimilation (learning) is the result of the repetition of a sequence of effects and reactions.

2. The principle of "learning through conditional reflexes" is formed through repetition.

3. When learning outcomes are encouraged (praised), learning outcomes increase. Attempts are being made today to complicate the stages, i.e. to complicate the exercises and to make the student practice several skills and processes at the same time in their implementation. The "Explanation" and "Demonstration" steps will be carried out step by step. This method is very effective in teaching practical skills from specialty subjects [4].

\section{DISCUSSION}

In the process of educational work it is important to teach students to think creatively, to change situations, to organize activities on the basis of free competition and to be able to use information technology, electronic textbooks and multimedia in practical training. This requires that students develop independence, free thinking, analysis of educational activities, professional development in the future become their internal need.

When lessons are conducted with extensive and effective use of interactive teaching methods, game technologies, the student develops active and logical thinking skills, speech culture, attention, logical memory, mental ability. In interactive teaching methods, students are the central figure of the learning process, where the learning process is based on the needs of students. It is effective for students to master the lesson if the teaching methods are interconnected.
In the process of educational work, it is important to teach students to think creatively, to change situations, to organize activities on the basis of free competition, and their ability to use pedagogical technologies in the classroom. This requires students to be independent, to cultivate free thinking, to analyze learning activities.

One of the important requirements for the organization of modern education is to achieve high results in a short time without spending excessive mental and physical effort. Delivering certain theoretical knowledge to students in a short period of time, building skills and competencies in a particular activity, as well as monitoring student performance, assessing the level of knowledge, skills and abilities acquired by them requires high pedagogical skills and a new approach to the educational process.

Today, a number of developed countries have accumulated extensive experience in this area, and the methods that form the basis of this experience are used in the educational process of interactive methods.

Reference text method. The reference text method was developed by German education practitioners and is theoretically based and scientifically improved. Research on improving the learning process in education shows that during practical training, some students learn the skill quickly, while others learn it slowly. As a result, if one student is willing to learn quickly and learn a new skill, the benefits of a new hands-on activity for the other will be minimal. That is, students 'interest is partially lost. With the help of the reference text, an opportunity for independent learning is created and each student will be able to acquire the necessary knowledge for a new skill.

In the reference text method, the student performs six steps. Dividing the learning 
process into such stages encourages students to learn independently. The student develops questions or assignments that are focused on a specific learning goal. In the "Data Collection" and "Planning" stages, students are given written documents such as kinematic diagrams, tables, notes, instructions. Such documents help students to gather information independently. The teacher motivates the students to act towards a specific goal and controls their work. The student will remain an active participant in their education. Now he is not only a listener, but also collects the necessary information for the task to be performed, plans the schedule and time of the lesson, evaluates the results of the work done [5].

Actions within the reference text method are performed as follows.

1. Data collection. At this stage, the teacher gives the students all the resources they need and specific questions. The questions are given to the students in the form of a step-by-step data collection procedure. These questions are called "Referral Questions". The answers to the referral questions are a set of information needed to complete the assignment. This means that students analyze the assignment given to them and collect information about the stages of work or the required raw materials on the basis of textbooks, teaching aids, diagrams and other technical documents. To do this, the assignment in the referral questions uses information about learning objectives.

2. Planning. At this stage, students independently develop a work plan, i.e., they plan the work steps they will undertake (e.g., the processing process, selection of materials, equipment, and tools) that will focus on the task at hand. In doing so, students rely on their initial theoretical knowledge and use personal notes.

3. Decision making. Students, together with the teacher, decide on the implementation of the plan. If different solutions emerge in solving the problem, then the most effective solution is chosen. The teacher should always be present as a counselor.

4. Implementation. Students do their homework according to a plan, and the teacher supervises their work. Mastery results are based on indicators such as accuracy, precision, stability, high quality.

5. Checking. Students check the results of their assignments (for example, quality indicators) on their own and record them on the evaluation sheet. Students can check each other's work. The teacher writes the results on a "summary" sheet.

6. Draw conclusions. The teacher analyzes the work process and results, conducts a final interview, and tells what to focus on next time. The essence of the reference text method is that students should study as independently as possible [6]. Therefore, didactic and exercise materials should be structured in such a way that they are primarily focused on independent learning. Assignments for students should be clearly defined, that is, they can be performed effectively in terms of learning, and in terms of size and complexity should meet the defined learning content. Independent work of students is highly effective in mastering, that is, they develop skills such as communication, planning, decision-making and self-examination. In addition, the expected outcome of student work is that they must plan and implement their work based on economic criteria (austerity). For example, they need to know how to use economical production methods, how to use materials or energy efficiently. 
Based on theoretical and practical experience in the application of the method of reference text in the learning process, the following conclusions can be drawn: the basis of the learning process is the work performed independently; work activities should be independently planned, implemented, inspected and evaluated by students; work activities should cover technical, occupational safety, legal, environmental and other issues; work actions should become a cognitive experience for students [7].

The project method is closely related to the reference text method, and these two methods differ from each other as follows. The reference text method focuses on independent study; the project method, in addition to independent learning, focuses on learning the personal skills and abilities needed to pursue a career.

The project method is used in particular to learn how to work with projects and to enhance mastery. The project method is called "Education for projects and the application of existing knowledge in a new situation" in European countries. The project should mainly serve learning, link theory and practice, be relevant to any work process encountered in the enterprise, and help students create independent plans, organize and implement work.

In vocational education, an equipment or part of a project can be an example. In order to apply the project method in the whole practical training process, the projects should be as follows:

1. A clearly defined task, such as a job description from planning to quality control, should be provided.

2. The task should be complex in terms of students and require them to apply existing knowledge in other situations, that is, the student should be forced to use other knowledge and skills in addition to existing knowledge in solving the problem.

3. It is required to strive to complete the new task according to the plan and as independently as possible through the acquired knowledge and skills. The main goal of the project method is that all the knowledge and skills needed to complete the task should be learned throughout the process. Students work together as a project team from independent planning to implementation and inference, sharing tasks as they complete a given task. The teacher monitors and manages the learning process on a regular basis [8].

\section{CONCLUSIONS}

We will consider the implementation of the project method step by step.

1. Data collection. For this stage, the intern must prepare documents and materials: project (schemes, technical drawings); description of relevant assignments in the project; referral questions; information about learning objectives. Students will be given a description of the project and assignment in the form of drawings and diagrams. The teacher is involved in analyzing the assignment using the questions that guide the students. Students collect information independently based on textbooks, manuals, and handouts. Students are given technical drawings so that they can copy the parts they need from these drawings into their documents. Students then create work steps to complete the project.

2. Planning. At this stage, students complete the work plan independently. This plan provides information on the stages of the work, is the technological sequence and 
the time allotted for them, the necessary equipment and facilities, and occupational safety measures.

3. Making decision. Students discuss the results that occur during the planning phase with the internship teacher. Different solutions are compared with each other, and the most optimal one is selected.

4. Implementation. Students complete the assignment independently based on the work plan. The internship teacher monitors the work process, records the results in a control book. The student is able to apply and develop the knowledge, which he / she has learned in a new situation and knows how to choose assessment and find new creative solutions.

5. Checking. Students check their own work results. For example, they can evaluate work results based on quality criteria.

6. Draw conclusions. The student and the internship teacher analyze the work process and results together. The purpose of the project method is to help students gain social and personal perspectives in addition to their knowledge and skills in their specialties.

Assessment of practical skills. Regular teaching of practical skills to students is one of the main features of vocational education. At the end of the practical exercise, a "test case" should always be conducted. Test work is a practical work is a manufactured product that is processed in accordance with the rules of the profession. The test work demonstrates the knowledge and skills the student has acquired. Through the test work, it is checked that the student completes any practical task on time. At the same time, the skills and abilities acquired by the student are identified. The results of the knowledge and skills previously acquired and learned by the students should be demonstrated in the test papers. Testing should be based on work that occurs directly in production. The test results should be evaluated against the established criteria.

In conclusion, teachers of higher education institutions can achieve their goals in cultivating mature graduates, of course, in collaboration with leading creators of manufacturing enterprises, by inculcating in students through new innovative technologies, agreeing on the knowledge they need to master in developing students' practical skills. In the teaching of special subjects, of course, it is advisable to organize the teaching process using the training laboratory rooms at industrial enterprises. Students apply their theoretical knowledge in practice using laboratory and production processes, developing and developing their practical skills. Professors need to make sure that students have developed practical skills and to address the gaps in students by assessing them on each topic.

During the study of vocational education subjects, students can analyze the content of education, to organize and develop pedagogical activities in them, to develop curricula and programs in the subjects, to independently study the problems of developing teaching methods.

Professors and teachers should set the following tasks and issues for the development of practical skills in students: Issues of principles of vocational education; methodological bases of vocational education methodology; psychological, pedagogical and methodological bases of theoretical knowledge in the field of specialization; the role of special disciplines in the formation and upbringing of students as individuals; principles and methods of teaching; creation of methodical base of sciences; scientific point of view of educational work; to develop students' 
creative thinking skills in public lessons and extracurricular production situations; reading, studying and analyzing methodological and educational literature; lesson planning; maintenance of planning documents; defining the goals and objectives of the planned internships in the curriculum of students; planning and organization of accounting and course work; covering topical issues such as the analysis of the material provision of teaching.

In our opinion, the above goal can be achieved through the use of advanced methods of learning in the teaching of vocational education subjects and practical skills in students, in the development of mature professionals for manufacturing enterprises.

\section{REFERENCES}

1. Resolution of the President of the Republic of Uzbekistan No. PD-2909 "On measures to further develop the system of higher education." 2017. www.lex.uz.

2. Abdullaeva K.M. Methodological bases of formation of professional knowledge and skills of future teachers in teaching special subjects: Autoref. dis.- T .: TDPU, 2006. - 22 p.

3. Begimkulov U.Sh. and others. Informatization of pedagogical education: theory and practice. Monography. Tashkent: Fan, 2011. - 232 p.

4. Assessment methods. Training manual. T .: O'MKHTRI, 2003. -155

5. Nuridinov B.S., Urinov U.A. Social cooperation in the field of education, a factor of training qualified personnel // Vocational education. - Tashkent, 2003. №6. B.11.

6. Olimov K.T., Ashurova S.Y., Urinov U.A. Modern educational technologies: Monograph. - Tashkent, 2007. - 96 p.
7. Urinov U.A. Social psychological priorities of social cooperation. European Journal of Research and Reflection in Educational Sciences. Great Britain. Progressive Academic Publishing. Vol.8, No.2, 2020, P 62-65

8. Urinov U. Status and problems of cooperation with higher educational enterprise enterprises. "International Journal of Psychosocial Rehabilitation" Volume 24 - Issue 8, 2020. P 5277-5282

9. Urinov U.A. Methods of formation of professional skills and abilities of students in the framework of social partnership in higher education. Scientific-theoretical and methodical journal "Pedagogical skills” Bukhara, 2019. №3 P. 76-79. 